\title{
Émile Durkheim, John Dewey e Antônio Gramsci: em debate a teoria da educação transformadora
}

Lorivaldo do Nascimento

Aparecida Favoreto

Universidade Estadual do Oeste do Paraná

\section{Resumo}

artigo analisa as concepções socioeducativas de três teóricos clássicos da educação: Durkheim, Dewey e Gramsci. Neste sentido, situando cada teórico em seu contexto histórico, busca-se compreender suas perspectivas educacionais em relação às suas concepções de transformações na e/ou da sociedade. Em comum, os autores elencados apresentam a escola como atuante socialmente, mas se distinguem na compreensão do processo histórico. Para Durkheim, a escola deve proporcionar a necessária harmonia moral para solucionar a grave crise da sociedade capitalista no final do século XIX. Dewey defende uma ampla reforma pedagógica, de modo a entrelaçar o conhecimento com as experiências individuais, permitindo a maior participação de todos na sociedade, renovando e ampliando a indústria, a ciência e a democracia capitalista. Gramsci, pressupondo que a estrutura capitalista é excludente, destaca que a escola, pelo princípio educativo do trabalho, pode formar indivíduos reflexivos, críticos e

250 capazes de atuar socialmente para romper com o sistema capitalista.

Palavras-chave: Teoria da transformação social. Educação. Escola.

\section{Émile Durkheim, John Dewey and Antônio Gramsci: in debate the theory of the transformative education}

\begin{abstract}
The article addresses the socio-educational conceptions of three classic theorists of education: Durkheim, Dewey and Gramsci. In this sense, placing each theoretical in its historical context, we seek to understand its educational perspectives in relation to the transformations in and/or of the society. In common, the authors presented the school as socially active, but distinguish themselves in the understanding of the historical process. For Durkheim, the school must provide the necessary moral harmony to solve the serious crisis of capitalist society in the late nineteenth century. Dewey advocates a broad pedagogical reform, in order to interweave knowledge with individual experiences, allowing greater participation of all in society, renewing and expanding industry, science and capitalist democracy. Gramsci, assuming that the capitalist structure is exclusive, emphasizes that school, through the educational principle of work, can form reflexive, critical individuals capable of social action to break with the capitalist system.
\end{abstract}

Keywords: Theory of social transformation. Education. School. 


\section{Émile Durkheim, John Dewey y Antonio Gramsci: en debate la teoría de la educación transformadora}

\section{Resumen}

El artículo analiza las concepciones socioeducativas de tres teóricos clásicos de la educación: Durkheim, Dewey y Gramsci. En este sentido, situando cada teórico en su contexto histórico, se busca comprender sus perspectivas educativas en relación a sus concepciones de transformaciones en la y/o de la sociedad. En común, los autores enumerados presentan la escuela como actuante socialmente, pero, se distinguen en la comprensión del proceso histórico. Para Durkheim, la escuela debe proporcionar la necesaria armonía moral para solucionar la grave crisis de la sociedad capitalista a finales del siglo XIX. Dewey defiende una amplia reforma pedagógica, de modo a entrelazar el conocimiento con las experiencias individuales, permitiendo la mayor participación de todos en la sociedad, renovando y ampliando la industria, la ciencia y la democracia capitalista. Gramsci, presuponiendo que la estructura capitalista es excluyente, destaca que la escuela, por el principio educativo del trabajo, puede formar individuos reflexivos, críticos y capaces de actuar socialmente para romper con el sistema capitalista.

Palabras clave: Teoría de la transformación social. Educación. Escuela.

\section{Introdução}

No hodierno contexto sociopolítico brasileiro, observam-se alterações em todos os âmbitos: social, cultural, econômico e político. Essas mudanças permeiam direta ou indiretamente a escola, modificando alguns aspectos de seu processo educativo, assim como influencia o debate sobre seus fins e objetivos. As mudanças que ocorrem, de forma sistematizada, buscam adaptar a educação escolar às novas demandas sociais, o que faz questionar se, a partir da educação e, mais especificamente da escola, a sociedade, no seu conjunto, pode ser transformada, constituindo uma nova forma de ser social. Ou seja, no processo histórico, a escola ocupa em relação ao conjunto da sociedade um papel de seguimento ou de protagonismo? Por seguimento se entende a necessidade de adequação do âmbito escolar às demais esferas sociais, as quais passaram por transformações. Por protagonismo se compreende o papel da escola como agente de transformação da sociedade. Esse questionamento permeia este artigo e se constitui como objeto de análise do pensamento de clássicos sociólogos da educação como: Émile Durkheim (1858-1917), John Dewey (1859-1952) e Antônio Gramsci (1891-1937). 
artigo encontra-se dividido em três pontos; cada um deles analisa o pensamento socioeducativo de um dos autores mencionados. Émile Durkheim quer encontrar, na educação, o elemento necessário para construir a harmonia social, podendo, assim, solucionar a crise capitalista do final do século XIX e início do século XX (LUCENA, 2010). John Dewey, nas primeiras décadas do século XX, propõe uma ampla reforma pedagógica. $\bigcirc$ autor defende que a prática pedagógica deve adaptar-se às necessidades históricas da democracia capitalista. Para isto, a própria escola deve proporcionar aos estudantes a vivência da participação, da responsabilidade e da democracia (CUNHA, 200 1). Antônio Gramsci, nas décadas de 1920 e 1930, consciente de que a escola tradicional e/ou a ativa estavam a serviço da manutenção do sistema capitalista, propõe a escola única. $\bigcirc$ autor acredita na transformação da escola e da metodologia de ensino como forma de desenvolver a consciência crítica do educando para que ele possa participar das decisões políticas e contribuir para a transformação social (JOVINE, 1977).

A escola é uma instituição social que está inserida em um contexto marcado por luta entre interesses diferentes, tanto no aspecto cultural quanto no político-econômico. Neste sentido, não se compreende a escola como um

252 fenômeno isolado. Ao contrário, ela se constitui na inter-relação entre elementos diversos, os quais compõem uma forma de ser social. Nesse processo de composição, a escola pode ser tanto protagonista como seguimento, a qual, diante das contradições gera possibilidades diversas de transformações ou de manutenção da ordem. Assim, cabe à escola oferecer aos educandos a capacidade de interpretarem o movimento da sociedade, de modo a tomarem suas posições.

\section{Emile Durkhiem e a educação como reprodução social}

Emile Durkheim foi o primeiro autor clássico a afirmar a educação como processo social, como fenômeno social capaz de ser descrito, analisado e explicado sociologicamente (SEBASTIÃO, 2009). Segundo Lopes (2012), Durkheim é o fundador da Socilogia da Educação na medida em que defende que a finalidade e os objetivos da educação devem ser determinados pela sociologia. 
A teoria da educação durkheimiana inspira-se na sua teoria sociológica geral. Durkheim interessou-se desde cedo pela educação enquanto objecto de estudo sociológico; pelo carácter social-histórico do fenômeno educativo; pelos métodos de educação de cada sociedade em determinado período histórico; pela forma como uma sociedade disciplina e integra através da educação; pela forma como favorece a realização dos seus membros (LOPES, 2012 , p. 51.

A abordagem social desenvolvida por Durkheim, em que a educação ocupa destacada função, somente pode ser compreendida como resultante de um contexto socioeconômico e, consequentemente, educativo que é específico das últimas décadas do século XIX e das primeiras do século XX. Na atmosfera proporcionada pela denominada segunda revolução industrial, o sociólogo francês desenvolve suas concepções socioeducativas ressaltando as capacidades das forças coercitivas que determinam a conduta do indivíduo. Na correlação entre sociedade e indivíduo, a primeira é uma determinante, e exige que o indivíduo se adapte totalmente aos seus objetivos. A educação é o principal instrumento dessa adaptação (LEONEL, 1994).

Os desdobramentos da crise capitalista de 1870 suscitaram reações diversas na comunidade acadêmica. Emile Durkheim discorda das concepções otimistas de pensadores positivistas, incluindo Auguste Comte (1798-1857), cujas teorias propagavam os ideais do avanço social e dos progressos na construção da sociedade mais avançada da história da humanidade. Contemporâneos de Comte, Karl Marx (1818-1883) e Friedrich Engels ( 1820-1895) afirmavam que a crise era inerente ao próprio sistema capitalista, podendo levar ao seu declínio. Para Marx (Manifesto), a crise só seria superada por um novo sistema socioeconômico: o comunismo.

Durkheim, discordando tanto dos otimistas positivistas incapazes de enxergar a grave crise quanto das concepções que apregoavam o fim do sistema vigente, acreditava que os problemas do capitalismo existiam e pelo próprio capitalismo poderiam ser superados. Os problemas sociais eram, prioritariamente, originados na débil moral da época. Por isto, defendia uma rígida disciplina como meio de superação da crise na sociedade industrial. A crise expressava a urgência da construção de uma moral coletiva, condição fundamental para a manutenção da sociedade capitalista. A aproximação efetuada 
Émile Durkheim, John Dewey e Antônio Gramsci: em debate a teoria da educação transformadora

por Durkheim dos pressupostos de Immanuel Kant (1724-1804) orientados à moral e ao ordenamento social sustenta o referido propósito (LUCENA, 2010).

Para Durkheim, a sociedade capitalista é mantida pela rígida divisão do trabalho. Por meio da educação, esta prepara os trabalhadores de que necessita. A tese de doutorado do autor, intitulada A Divisão do Trabalho Social, publicada em 1893, debateu as complexas relações entre indivíduo e sociedade. $\bigcirc$ modo como os indivíduos constituem a sociedade e o consenso é o tema que fundamenta e permeia a obra. Para Durkheim, o indivíduo nasce da sociedade e não a sociedade nasce do indivíduo. A divisão do trabalho é estrutura de toda a sociedade, de que a divisão técnica ou econômica do trabalho não passa de uma manifestação (DURKHEIM, 1978).

$\bigcirc$ primado da sociedade sobre o indivíduo é, no pensamento durkheimiano, uma tese central e imprescindível à compreensão das concepções educacionais. Na obra Educação e Sociologia, Durkheim expõe que a influência das coisas sobre os homens é diversa daquela que provém dos próprios homens; e a ação dos homens pertencentes à mesma faixa etária difere daquela que os adultos exercem sobre os jovens. É esse conjunto de influências que Durkheim (2012) denomina como Educação.

Durkheim (2012) apresenta uma peculiar visão sociológica sobre o fenômeno educacional. A sua reflexão se move, em primeiro lugar, como crítica à concepção individualista da educação predominante desde Kant à Stuart Mill (1 806-1873), a qual prioriza o desenvolvimento das potencialidades individuais com o objetivo específico de levar o indivíduo à plena humanização.

Para Durkheim, a educação não pode ser compreendida sem a supracitada compreensão do primado da sociedade sobre o indivíduo:

Porém na verdade, cada sociedade, considerada em determinado momento de seu desenvolvimento, tem um sistema de educação que se impõe aos indivíduos com uma força geralmente irresistível. Não adianta crer que podemos educar nossos filhos como quisermos. Há costumes aos quais somos obrigados a nos conformar; se os transgredirmos demais eles acabam se vingando em nossos filhos. Uma vez adultos, estes últimos acreditarão não poder em meio aos seus contemporâneos com os quais não estão em harmonia. Pouco importa se foram criados com ideias arcaicas ou avançadas demais; tanto em um caso como no outro, eles não terão condições de viver uma vida normal. Portanto, em qualquer época, existe um tipo regulador de educação do qual não podemos nos distanciar 
sem nos chocarmos com vigorosas resistências que escondem dissidências frustradas (DURKHEIM, 2012, p. 47-48).

A citação acima expõe as principais teses do pensamento educacional durkheimiano. A concepção de primado da sociedade sobre o indivíduo acima citada é compreendida como necessidade de harmonização do último para com a primeira: educar é harmonizar. $\bigcirc$ progresso é alcançado em uma contínua evolução histórica, ou seja, sem rupturas. É verdade que a educação não é um fenômeno universal, mas histórico que se transforma com o transformar-se da sociedade. Para Durkheim (2012), desvincular-se dos condicionamentos sociais e educar segundo princípios subjetivos traz insuperáveis danos ao educando.

As concepções educacionais de Émile Durkheim apresentam, no confronto com concepções pedagógicas anteriores - como as de Stuart Mill e Immanuel Kant citadas na obra Educação e Sociologia -, uma notória valorização da historicidade da prática educativa. Durkheim (2012, p. 55) defende que a educação transforma o homem e a sociedade, pois "[...] ela cria um novo ser no homem". Porém, a educação segue a ordem evolutiva da sociedade capitalista descoberta pela ciência moderna. Desta forma, transformação não é ruptura, mas adequação. Através da educação, a sociedade atinge o ponto de harmonia que possibilita a contínua evolução da ordem capitalista.

Durkheim parte do fato de que o indivíduo é produto da sociedade. Raymond Aron (2013, p. 464), parafraseando Durkheim, escreve: "[...] o indivíduo nasce da sociedade e não a sociedade do indivíduo". A educação escolar consiste em uma socialização metódica das novas gerações (DURKHEIM, 2012). Para que haja educação, é preciso que uma geração de adultos e uma de jovens se encontrem face a face e que uma ação seja exercida pelos primeiros sobre os segundos:

A educação é a ação exercida pelas gerações adultas sobre aquelas que ainda não estão maturas para a vida social. Ela tem como objetivo suscitar e desenvolver na criança um certo número de estados físicos, intelectuais e morais exigidos tanto pelo conjunto da sociedade política quanto pelo meio específico ao qual ela está destinada em particular (DURKHEIM, 2012, p. 53-54, grifos do autor). 
Émile Durkheim, John Dewey e Antônio Gramsci: em debate a teoria da educação transformadora

Cada sociedade constrói um modelo de homem e um modelo de educação. A educação deve reproduzir o ideal de homem elevado como modelo pela sociedade. Essa concepção se encontra na seguinte passagem da supracitada obra Educação e Sociologia:

O resultado desses fatos é que cada sociedade elabora um certo ideal do homem, ou seja, daquilo que ele deve ser tanto do ponto de vista intelectual quanto físico e moral; que este ideal é, em certa medida, o mesmo para todos os cidadãos; que a partir de certo ponto ele se diferencia de acordo com os meios singulares que toda sociedade compreende em seu seio. É este ideal, único e diverso ao mesmo tempo, que é o polo da educação. Portanto, a função desta última é suscitar na criança: $1^{\circ}$ ) um certo número de estados físicos e mentais que a sociedade à qual ela pertence exige de todos os seus membros; $2^{\circ}$ ) certos estados físicos e mentais que o grupo social específico (casta, classe, família, profissão) também considera obrigatório em todos aqueles que o formam. Assim, é o conjunto da sociedade e cada meio social específico que determinam este ideal que a educação realiza (DURKHEIM, 2012, p. 52-53).

Para ele, cada sociedade elabora seu modelo ideal de homem a ser formado pela educação, de modo que as gerações mais velhas não podem educar as mais novas ignorando o fato social (DURKHEIM, 2012). $\bigcirc$ próprio sistema educacional não pode ser livremente modificado pelo educador:

[Sistemas educacionais são] realidades existentes, as quais ele [o reformista social] não pode nem criar, nem destruir, nem transformar à vontade. Ele só pode influenciá-las na medida em que aprender a conhecê-las e souber qual é a sua natureza e as codições das quais elas dependem; e só conseguirá saber tudo isto se seguir o seu exemplo, se começar a observá-las, como o físico o faz com a matéria bruta, e o biólogista, com os seres vivos (DURKHEIM, 2012, p. 49).

Durkheim admite certa diversidade social, desde que não haja uma contradição na homogeneidade, de modo especial, na perspectiva moral. A sociedade capitalista, com seu sistema produtivo altamente dividido e complexo, somente vive se existir uma homogeneidade suficiente entre seus membros. Da análise social, Durkheim (2012) deduz a tarefa da educação, a qual consiste em perpetuar e fortalecer a homogeneidade, gravando, 
previamente, na criança as essenciais semelhanças exigidas pela coletividade em que se encontra inserida.

Para Durkheim (2012), cada sociedade possui um ideal de homem sendo responsabilidade e tarefa da educação a sua formação. A análise histórica mostra, segundo o autor, a profunda dependência da educação em relação aos sistemas sociais.

A pergunta inevitável: qual o ideal de homem que a sociedade capitalista da segunda revolução industrial possui e a educação tem a tarefa de formar? $\bigcirc$ apelo durkheimiano aos imperativos da moral kantiana demonstra que, para Durkheim, a educação consiste, antes de tudo, no desenvolvimento do espírito da moral e da harmonia social. Ensinar a moral significa fornecer os meios necessários para que o educando possa adquirir conhecimentos e disciplina para que possa exercer o autocontrole sobre suas reações espontâneas e aprender, desta forma, a viver em sociedade.

Em relação ao processo histórico, Durkheim pressupõe que a escola pode formar um novo ser no homem, contribuindo, assim, para superar os problemas gerados pela sociedade industrial. Entretanto, tal pressuposto não implica em rompimento com a sociedade, mas adequação do indivíduo ao desenvolvimento e ao progresso social.

\section{John Dewwy: a escola democrárica}

John Dewey foi o continuador da doutrina filosófica, denominada Pragmatismo iniciada por Willian James (1842-1910) e Charles Sanders Peirce (1839-1914) que preconiza que todo o aprendizado e conhecimento devem ter um fim prático. Dewey é influenciado pelo evolucionismo no campo das ciências naturais e pelo positivismo nas ciências humanas. Essa dupla influência é manifestada nos conceitos de natureza e experiência (DEWEY, 1980) que são, pelo autor, inseridos no contexto socioeducacional (DEWEY, 1979).

A educação que na antiguidade, no medievo e mesmo na modernidade, foi considerada uma prática fundamentada na ética ou na filosofia e/ ou na teologia, com John Dewey começa a ser considerada uma ciência autônoma em constante diálogo com outras ciências ou áreas do conhecimento, tais como a psicologia e, especialmente, a sociologia. 
Assim como Durkheim, Dewey ressalta a dimensão sociológica da educação. Para ele, é um processo, através do qual o indivíduo, desde o nascimento, assimila os conhecimentos, as técnicas, os hábitos de vida que a civilização humana produziu ao longo de seu desenvolvimento. $\bigcirc$ caráter social da educação deve revestir todos os aspectos do processo educativo. A finalidade da escola consiste em favorecer a socialização e o desenvolvimento intelectual do indivíduo. A escola deve ensinar as noções e estimular o desenvolvimento das capacidades, em modo especial, a articulação entre conteúdo e vida e o exercício da democracia, que a sociedade capitalista tem necessidade (JYAN, 1926).

Dewey compreendeu a educação como um instrumento concreto para a superação da crise que atingia o mundo capitalista. $\bigcirc$ objetivo da educação não é permanecer no passado, tampouco construir utopias, mas tornar os estudantes conscientes do mundo onde vivem. Se for incapaz de construir essa consciência, a escola não oferece nenhum contributo para que a sociedade supere a crise (LICHTNER, 2009).

Temas sempre presentes nas obras de Dewey é a relação entre a educação, a escola e a sociedade e, neste aspecto, ele pontua o papel da 258 pedagogia na formação do homem necessário para a sociedade industrializada, democrática e em constante mudança. Particularmente, no seu Credo pedagógico, ele pontua a interação entre o aspecto psicológico (individual) e o social, firmando que a tarefa fundamental da escola é desenvolver as capacidades individuais e, ao mesmo tempo, adaptar o indivíduo à sociedade. Para ele, não existe contradição entre as duas exigências, pois, em uma sociedade democrática, as capacidades individuais devem ser empregadas em benefício da sociedade (LICHTNER, 2009).

A educação, para Dewey, apresenta um enfoque político- democrático. Em uma de suas principais obras, cujo título é sugestivo, Democracia e educação, ele concebe a prática educacional simultaneamente como necessidade e função social. A educação é o processo social que possibilita aos grupos sociais a continuidade de suas existências. Neste sentido, toda sociedade e todo grupo social necessitam da educação, principalmente, a sociedade moderna que, diante de sua complexidade, aumenta a diferença entre a capacidade dos mais novos e os interesses dos adultos. Para Dewey (1959, p. 8), sem a "[...] educação formal é impossível a transmissão de todos os recursos e conquistas de uma sociedade complexa". Dessa forma, no 
contexto socioeconômico de passagem do século XIX ao XX, o autor considera a educação escolar essencial para se concretizar a sociedade democrática, além de ser um instrumento necessário na propagação dos valores sociais (SCHMIDT, 2009).

A democracia, para o autor, não é apenas um sistema de governo, mas também uma forma de vida associada, de experiências comuns reciprocamente comunicadas. Assim, na obra Democracia e educação, escreve que: "[...] uma sociedade é democrática na proporção em que prepara todos os seus membros para com igualdade aquinhoarem de seus benefícios e em que assegura o maleável reajustamento de suas instituições por meio da interação das diversas formas da vida associada" (DEWEY, 1959, p. 106). A escola, no cumprimento da função social que dela espera a sociedade, deve oferecer aos indivíduos um tipo de educação que propicie hábitos sociais que permitam mudanças sociais sem ocasionar desordem. Enfim, é possível sintetizar a função social da educação como construção e aprimoramento da sociedade democrática (SCHMIDT, 2009).

A organização escolar deve, também, ser concebida como uma organização democrática que estimula os espíritos à participação e à corresponsabilidade. A escola deve, por consequência, ser ela mesma vida e não preparação para uma vida futura. Não deve preparar as novas gerações para uma futura experiência democrática, mas ela mesma, precisa ser entendida como um local privilegiado de experiências democráticas. Dewey (1980) propõe a escola como um laboratório da vida social, uma vez que reflete, de imediato, todas as nuances da sociedade, desde as diferenças culturais e cognitivas até as econômicas.

Assim, ele defende a Pedagogia experimental como método que poderia criar um novo hábito?. Para ele, essa pedagogia poderia mudar o congnitivo da criança para ter atitudes mais participativas.

Na obra intitulada Vida e educação, Dewey escreve:

A escola deve assumir a feição de uma comunidade em miniatura, ensinando situações de comunicação de umas a outras pessoas, de cooperação entre elas, e ainda, estar conectada com a vida social em geral, com o trabalho de todas as demais instituições: a família, os centros de recreação e trabalho, as organizações da vida cívica, religiosa, econômica, política (DEWEY, 1967, p. 8). 
Segundo Lichtner (2009), educar para a democracia significa em Dewey levar os jovens a dividir os valores, modos de ser e comportamentos individuais e sociais. Isso não é obtido apenas com algumas lições de educação cívica, mas também desenvolvendo uma valência educativa de todas as matérias de estudo, sejam elas humanísticas e/ou das ciências naturais, e, sobretudo fazendo experiências já na escola de um modo de viver democrático.

John Dewey é considerado, igualmente, o iniciador do denominado "ativismo pedagógico". Corrente essa que parte da concepção de que o educando é sujeito ativo e protagonista nos processos de aprendizagem. Aspectos centrais, no ambiente educacional, não são as lições em si mesmas, mas as atitudes e as capacidades a estas conexas. Em modo particular, o desejo, o experienciar e a capacidade de aprender na escola. Deste modo, conservará essa habilidade por toda a sua vida e continuará a aprender em todas as situações.

Assim como, posteriormente fará Antônio Gramsci, John Dewey empreenderá severas críticas à educação tradicional. A esse respeito, escreve Helena Bomeny:

A crítica de Dewey à educação conservadora é que ela nega a existência das faculdades e exagera o papel exclusivo da matéria de estudo para o desenvolvimento mental e moral, uma edificação feita, de fora para dentro, no espírito. Desconsiderando a consciência, a inteligência, a educação reifica o processo imobilista de introjeção de conteúdo externo. A doutrina que inspira a educação conservadora subentende níveis de estruturação da consciência que desembocam em um método uniforme para todas as matérias e para todos os alunos de todas as idades (BOMENY, 2005, p. $11-121$.

A Escola não é democrática quando não considera suficientemente a diversidade dos educandos. No que diz respeito aos objetivos ou fins da educação em uma comunidade democrática, o primeiro problema a resolver é definir a natureza de um objetivo que exista no interior de uma atividade, em vez de the ser exteriormente fornecido (SCHMIDT, 2009). Na obra Democracia e educação, Dewey escreve: 
Falar-se em objetivo ou fim da educação quando quase todos os atos de um discípulo são impostos pelo professor, quando a única ordem na sequência de seus atos é proveniente das lições marcadas e das direções dadas por outrem é absurdo. Como se torna igualmente ridículo falar-se em fins ou objetivos quando se permite a atividade caprichosa ou descontínua, sob o pretexto da manifestação espontânea da personalidade. Um objetivo ou um fim importa em atividades seriadas e ordenadas, atividades cuja ordem consiste no progressivo completar-se de um processo. [...]. Por essa causa é disparate falar-se em objetivo da educação - ou de outra qualquer empresa - se as condições não permitem a previsão dos resultados e nem incitarem uma pessoa a encarar o futuro, procurando prever as consequências de determinado modo de proceder (DEWEY, 1959, p. 110 ).

A educação tradicional habitua a criança à docilidade e obediência. Treina a execução conscienciosa de tarefas impostas, muitas vezes sem que se conheça o seu objeto. Dewey afirma que a fundamental tarefa do processo educativo é garantir a continuidade dos grupos sociais, bem como contribuir com a reconstrução e reorganização da sociedade capitalista democrática. $\bigcirc$ autor prioriza o aprender fazendo, combinando experiência e aprendizagem em um processo contínuo.

Em termos gerais, para Dewey, a pedagogia experimental poderia desenvolver a consciência reflexiva e participativa nos educandos, de modo que todos se tornassem preparados para o desenvolvimento industrial e para a democracia capitalista. Neste sentido, semelhante a Durkheim, Dewey pressupõe que a escola poderia contribuir na resolução dos problemas gerados pelo desenvolvimento da sociedade capitalista. Todavia, enquanto Durkheim parte de uma reflexão sobre a moral social, em que o indivíduo teria que se adequar aos valores sociais, Dewey prioriza o aspecto pedagógico, pressupondo que o desenvolvimento das capacidades cognitivas individuais poderia contribuir para o progresso social. Entretanto, cabe salientar que, tal progresso não implica um rompimento com as estruturas do capital, mas preparação dos indivíduos para participar e usufruír da riqueza material e cultural da sociedade. 


\section{Antonio Gramsci e a escola única}

No que tange ao contexto sociopolítico e econômico, o pensamento de Antônio Gramsci encontra-se situado em um importante momento de transformação da história contemporânea. $\bigcirc$ filósofo marxista italiano nasce na última década do século XIX, logo após a morte de Karl Marx, quando os embates em torno da interpretação do pensamento marxista e sua aplicação direta à vida política europeia ecoavam na II Internacional. Os debates entre revisionistas como Kautsky (1854-1938), o Partido oficial e setores mais radicais como aqueles ligados à Rosa Luxemburgo (1871-1919) rompiam a unidade comunista. Quando Gramsci inicia sua militância política em Turim, o socialismo é sacudido pela revolução russa (1917), as discussões em torno da III Internacional e, posteriormente a disputa interna na Rússia que envolve Lênin (1870-1924) e, principalmente, Trotsky (1879-1940) e Stalin (1878-1953). Na sua Itália, a esquerda se divide entre o partido Socialista Italiano (PSI) e o Partido Comunista Italiano (PCI) que tem nele (Gramsci) um dos fundadores. No mesmo período, o nazismo na Alemanha e o fascismo na ltália conquistam o poder. Essas circunstâncias históricas levarão, logo após a morte de Gramsci,

262 àll Guerra Mundial.

Nesse contexto agitado, Gramsci desenvolve suas concepções educacionais e pedagógicas. A educação gramsciana é inseparável da sua vida política e social, na qual encontra sua fundamentação e finalidade. No que diz respeito especificamente à escola, o filósofo italiano encontra-se situado, logo após as teorias de Dewey e a denominada Escola Nova e/ou Ativa. $\bigcirc$ pensamento educativo e pedagógico de Gramsci encontra-se exposto, em modo especial, nos Cadernos 04 e 12 da obra intitulada "Cadernos do Cárcere" (GRAMSCI, 2000). Todavia, na totalidade das obras do autor, encontram-se importantes referimentos ao tema. Esta pesquisa, consciente de seus limites, se restringe à análise dos Textos dos "Cadernos do Cárcere" e das "Lettere dal Carcere".

Assim como Dewey, Gramsci apresenta, em suas obras, severas e pesadas críticas à escola tradicional que nos seus escritos é, geralmente, denominada como jesuítica (GRAMSCl, 2000). Nos seus escritos juvenis e em suas cartas, o autor descreve a escola que frequentou como autoritária e discriminatória. Ainda no ensino elementar, foi advertido por um diretor que the faz menção aos 84 artigos do regimento escolar (GRAMSCI, 1971). Em suas 
cartas, descreve que, desde a infância, era inclinado para o estudo das ciências exatas, mas não encontrou um professor que valesse um vintém².

No Caderno 12, o autor faz frequentes alusões à escola tradicional e desinteressada que se encontra ligada à formação dos intelectuais tradicionais, os quais consideram a si próprios como autônomos e independentes em relação aos grupos sociais, mas que, no cenário sociopolítico, encontram-se a serviço das classes dominantes (GRAMSCI, 2000). Assim, ele é consciente do caráter oligárquico da escola. Em uma passagem da obra analisada, se refere à escola tradicional afirmando que essa era oligárquica, pois era voltada à instrução da nova geração dos grupos dirigentes (GRAMSCl, 2000).

Com base nessas reflexões, fica claro que Gramsci (2000) é crítico da índole abstrativa da escola tradicional jesuítica que, para ele, é incapaz de abordar, organicamente, a relação teoria e prática e encontra-se separada da vida. Nos Cadernos do Cárcere (2000) e nas Lettere dal Carcere (1971), Gramsci faz frequentes alusões críticas às escolas profissionalizantes. $\bigcirc$ desenvolvimento industrial levou a quase abolição da escola clássica de formação geral humanística e priorizou as escolas profissionalizantes coma finalidade de fornecer operários técnicos para o trabalho fabril:

A tendência atual é a de abolir qualquer tipo de escola desinteressada (não imediatamente interessada) e formativa, ou de conservar apenas um seu reduzido exemplar, destinado a uma pequena elite de senhores e de mulheres que não devem pensar em preparar-se para um futuro profissional, bem como a de difundir cada vez mais as escolas profissionais especializadas, nas quais o destino do aluno e sua futura atividade são predeterminados (GRAMSCl, 2000, p. 331.

Entre os estudiosos existe discordância sobre o grau de conhecimento que Gramsci teve das concepções de Dewey e da Escola Nova e/ou Ativa. Dario Ragazzini, (1976, p. 207), pedagogo italiano e professor de história da educação, afirmou que "Gramsci não conhecia o ativismo pedagógico verdadeiro e próprio, tanto que, nos Cadernos do Cárcere, o nome de Dewey aparece apenas uma vez" Todavia, como cita Daniela Martinez, entre as obras de pedagogia que Gramsci possuía no cárcere se encontrava a L'ecole active de Adolphe Ferrière ${ }^{3}$. É necessário recordar, igualmente, que, no início do século XX, as revistas italianas II Leonardo e La Voce haviam, já havia 
Émile Durkheim, John Dewey e Antônio Gramsci: em debate a teoria da educação transformadora

difundido o pensamento de Dewey na busca por novos métodos e aproximações pedagógicas ${ }^{4}$. Da mesma forma, é importante considerar que, em 1913, Luigi Oliva ${ }^{5}$ havia traduzido para 0 italiano $\bigcirc$ meu credo pedagógico de Dewey (MARTINEZ, 2014).

Os fatos supracitados demonstram que Gramsci conheceu o pensamento pedagógico de Dewey. Tanto é que, em diversas passagens de sua obra, Gramsci (2000) direciona críticas à Escola Nova e/ou ativa, sendo tais críticas, ainda mais contumazes que aquelas dirigidas à escola jesuítica tradicional. A visão de totalidade gramsciana, a qual pressupõe que escola e educação se interligam com a política e a transformação, são as motivações pelas quais move contra as concepções escolanovistas as mais pesadas críticas. Na citação abaixo, Gramsci faz referência à suposta escola democrática, tão cara a John Dewey, que, na prática, é mais oligárquica que a escola tradicional:

A multiplicação de tipos de escola profissional, portanto, tende a eternizar as diferenças tradicionais; mas, dado que tende, nestas diferenças, a criar, estratificações internas, faz nascer a impressão de ter uma tendência democrática. Por exemplo; o operário manual e qualificado, camponês e agrimensor ou pequeno agrônomo, etc. Mas a tendência democrática, intrinsecamente, não pode significar apenas que um operário manual se torne qualificado, mas que cada cidadão possa se tornar governante e que a sociedade o ponha, ainda que abstratamente, nas condições gerais de fazê-lo: a democracia política tende a fazer coincidir governantes e governados (no sentido de governo com o consentimento dos governados), assegurando a cada governando o aprendizado gratuito das capacidades e preparação técnica geral necessárias a essa finalidade. Mas o tipo de escola que se desenvolve como escola para o povo não tende mais nem sequer a conservar a ilusão, já que ela cada vez mais se organiza de modo a restringir a base da camada governante tecnicamente preparada, num ambiente sociopolítico que restringe ainda mais a iniciativa privada, no sentido de dar esta capacidade e preparação técnico-políitica, de modo que, na realidade, retorna-se às divisões em ordens juridicamente cristalizadas em vez de superar as divisões em grupos: a multiplicidade das escolas profissionais, cada vez mais especializadas desde o início do currículo escolar, é uma das mais evidentes manifestações desta tendência (GRAMSCI, 2000, p. 49-50). 
Para Gramsci, as escolas profissionais, assim como as clássicas, não formam o intelectual orgânico. As últimas formam intelectuais "desinteressados" e incapazes de incidir sobre a prática social, as primeiras formam técnicos de fábrica, cuja função pode ser comparada à dos oficiais subalternos do exército, ou seja, não possuem iniciativa autônoma e não exercem nenhuma função política sobre suas massas instrumentais. Ao contrário, muitas vezes, são os intelectuais orgânicos da massa que exercem influência política sobre os técnicos de fábrica (GRAMSCl, 2000).

Após criticar tanto a escola Tradicional Jesuítica quanto a escola Ativa de Dewey (embora sem citá-lo diretamente), Gramsci propõe a concepção de Escola Única, a qual, para ele, deve estar orientada a formação do intelectual orgânico do proletariado. Gramsci é consciente de que a escola, seja a tradicional e/ou burguesa, está a serviço das classes dominantes e serve para a manutenção do sistema vigente. Entretanto, o filósofo marxista italiano afirma que é possível e, mesmo necessário, se utilizar da escola do presente para objetivar uma futura transformação da sociedade, rompendo definitivamente com a estrutura capitalista e, em consequência uma nova escola, a serviço da emancipação humana.

Para a compreensão desses fundamentais conceitos gramscianos, os temas do Caderno 12 devem ser confrontados com aqueles dos cadernos 8, 13, 15 e 18 que abordam temas mais diretamente políticos relacionados ao novo príncipe, ou seja, o Partido Comunista. Escola e política encontram-se no pensamento de Gramsci em permanente relação dialética. A escola é produto da sociedade, mas, a partir da Escola Criativa, é possível a práxis reflexiva para a transformação social e o surgimento de uma nova ordem mundial.

No Caderno 04, Gramsci utiliza o presente do indicativo em menção à transformação escolar já em curso na Rússia. No Caderno 126, utiliza o condicional como referimento à escola a ser construída na ltália. Para formar o intelectual orgânico, a escola, para Gramsci, deve ser única. Nos supracitados cadernos, explica o funcionamento dela, incluindo períodos de aprendizagem, currículo escolar e investimentos governamentais:

A escola unitária deveria corresponder ao período representado hoje pelas escolas primárias e médias, reorganizadas não somente no que diz respeito ao método de ensino, mas também no que toca à disposição dos vários graus da carreira escolar. $\bigcirc$ nível inicial da escola elementar não deveria ultrapassar três-quatro anos e, ao 
Émile Durkheim, John Dewey e Antônio Gramsci: em debate a teoria da educação transformadora

lado do ensino das primeiras noções "instrumentais" da instrução (ler, escrever, fazer contas, geografia, história), deveria desenvolver, sobretudo a parte relativa aos "direitos e deveres", atualmente negligenciada, isto é, as primeiras noções do Estado e da sociedade, enquanto elementos primordiais de uma nova concepção do mundo que entra em luta contra as concepções determinadas pelos diversos ambientes sociais tradicionais, ou seja, contra as concepções que poderíamos chamar de folclóricas (GRAMSCI, 2000, p. 37).

Gramsci é consciente da defasagem de preparação e conhecimentos que atinge os alunos provenientes das classes subalternas na escola clássica. Os filhos de famílias intelectualizadas encontram já no ambiente familiar uma preparação, um prolongamento e uma complementação da vida escolar. Esses conhecem e desenvolvem o domínio da língua literária, absorvendo, antes da idade escolar, noções e aptidões que tornam mais fácil e proveitosa a vida escolar. Para a correção dessa discrepância, sugere a utilização de creches antes da idade escolar e monitoramento extraescolar durante a escola elementar:

Na organização interna da escola unitária, devem ser criadas, pelo menos, as mais importantes destas condições, além do fato, que se deve dar por suposto, de que se desenvolverá - paralelamente à escola unitária - uma rede de creches e outras instituições nas quais, mesmo antes da idade escolar, as crianças se habituem a uma certa disciplina coletiva e adquiram noções e aptidões pré-escolares. De fato, a escola unitária deveria ser organizada como escola em tempo integral, com vida coletiva diurna e noturna, liberta das atuais formas de disciplina hipócrita e mecânica, e o estudo deveria ser feito coletivamente, com a assistência dos professores e dos melhores alunos, mesmo nas horas do estudo dito individual, etc (GRAMSCl, 2000, p. 38).

Conforme já exposto, o intelectual orgânico, na concepção gramsciana, é capaz de articular teoria e prática em uma relação dialética, sendo detentor do materialismo histórico e crítico. Por este motivo, a escola do futuro, projetada por Gramsci, deveria proporcionar novas relações entre trabalho intelectual e trabalho produtivo: "[...] o advento da escola unitária significa o início de novas relações entre trabalho intelectual e trabalho industrial não apenas na escola, mas em toda a vida social" (GRAMSCl, 2000, p. 40). 
No currículo escolar proposto por Gramsci, o período escolar, denominado Liceu (Ensino Médio), teria a função de integrar os estudos à vida profissional e produtiva como ponte entre o ensino fundamental e a universidade:

Por isso, na escola unitária, a última fase deve ser concebida e organizada como a fase decisiva, na qual se tende a criar os valores fundamentais do 'humanismo', a autodisciplina intelectual e a autonomia moral necessária à uma posterior especialização, seja ela de caráter científico (estudos universitários), seja de caráter imediatamente prático-produtivo (indústria, burocracia, comércio, etc.). $\bigcirc$ estudo e o aprendizado dos métodos criativos na ciência e na vida devem come $c$ çar nesta última fase da escola, não devendo mais ser um monopólio da universidade ou ser deixado ao acaso da vida prática: esta fase escolar já deve contribuir para desenvolver o elemento da responsabilidade autônoma nos indivíduos, deve ser uma escola criadora (GRAMSCl, 2000, p. 39).

Não é possível separar o homo faber do homo sapiens (GRAMSCl, 2000). A escola tem a função de despertar o intelectual que se encontra em cada homem ou, utilizando a terminologia de Gramsci, de desenvolver o homo sapiens que se encontra em cada homo faber. Nas primeiras páginas do Caderno 12, o autor escreve que um mínimo de intelectualidade é encontrado em todas as atividades:

Na verdade, o operário ou proletário, por exemplo, não se caracteriza especificamente pelo trabalho manual ou instrumental, mas por este trabalho em determinadas condições e em determinadas relações sociais (sem falar no fato de que não existe trabalho puramente físico, e de que mesmo a expressão de Taylor, do 'gorila amestrado', é uma metáfora para indicar um limite numa certa direção: em qualquer trabalho físico, mesmo no mais mecânico e degradado, existe um mínimo de qualificação técnica, isto é, um mínimo de atividade intelectual criadora) (GRAMSCl, 2000, p. 181.

Ao final do Caderno, Gramsci afirma que o processo educacional, mais precisamente pedagógico, consiste em, por meio da disciplina, desenvolver a intelectualidade já presente em cada ser humano, pois é impossível falar de homens não intelectuais: 
Émile Durkheim, John Dewey e Antônio Gramsci: em debate a teoria da educação transformadora

O problema da criação de uma nova camada intelectual, portanto, consiste em elaborar criticamente a atividade intelectual que cada um possui em determinado grau de desenvolvimento, modificando sua relação com o esforço muscular-nervoso no sentido de um novo equilíbrio e fazendo com que o próprio esforço muscular-nervoso, enquanto elemento de uma atividade prática geral, que inova perpetuamente o mundo físico e social, torne-se o fundamento de uma nova e integral concepção do mundo (GRAMSCl, 2000, p. 53).

Nas últimas linhas do Caderno 12, Gramsci (2000) descreve o novo intelectual formado na escola criadora e orientado para a prática política no partido ocupando a função de dirigente:

O modo de ser do novo intelectual não pode mais consistir na eloquência, motor exterior e momentâneo dos afetos e das paixões, mas numa inserção ativa na vida prática, comoconstrutor, organizador, 'persuasor permanentemente', já que não apenas orador puro - mas superior ao espírito matemático abstrato; da técnica-trabalho, chega à técnica-ciência e à concepção humanista histórica, sem a qual permanece 'especialista' e não se torna 'dirigente' (especialista + político) (GRAMSCI, 2000, p. 53).

A educação em Antônio Gramsci se constitui em um dos privilegiados instrumentos para a transformação da sociedade. Embora não seja a escola da nova ordem social, é ela, a escola que está em construção. As mudanças na vida social de um país, passam, necessariamente, pela escola, mesmo a escola burguesa, e serão, posteriormente, complementadas na ação prática da militância partidária. Desse modo, o proletariado terá, também, seus intelectuais orgânicos, os quais, compreendendo a sociedade em toda sua complexidade, mais do que trabalhadores especializados, poderão analisar criticamente sua realidade, de modo a encontrar possibilidades para a transformação social.

Para Gramsci, a transformação social implica em um rompimento com a estrutura capitalista que subordina a classe operária aos interesses do capital. Porém, é importante grifar que, nesse ideal, a escola, mesmo situada em uma luta política, ela não é, por si só, transformadora, mas ela pode oferecer instrumentos para a classe operária participar ativamente da luta política na sociedade civil. Dessa forma, Gramsci pontua um importante papel para a 
cultura, incluindo a escola, no processo de superação do capitalismo e criação de uma nova ordem mundial, ou seja, o comunismo.

\section{Considerações Finais}

Para finalizar, destaca-se que, entre os teóricos analisados, existe certa confluência, principalmente no que diz respeito às críticas ao sistema de ensino vigente e seus apontamentos quanto a escola ser um elemento social que pode influenciar no processo histórico e social.

Entretanto, em que pese tais confluências, a concepção de sociedade e de perspectiva transformadora, entre os teóricos analisados, são divergentes. De um lado, estão Durkheim e Dewey que, apesar de suas diferenças quanto ao cerne de análise, em comum, apresentam a educação como um fator social que pode contribuir na reconstrução e reorganização da sociedade capitalista democrática, não pressupondo o rompimento com a estrutura social. Assim, mesmo que Durkheim priorize a análise social e Dewey a pedagógica, ambos comungam da ideia de que a escola pode resolver os problemas sociais, sem romper, necessariamente, com a ordem capitalista. Por outro, situa-se Gramsci que, considerando a educação um importante instrumento de conscientização, pontua a escola como um dos privilegiados aparelhos no desenvolvimento da consciência crítica para a transformação social. Neste sentido, compreende que a escola pode contribuir para a superação do capitalismo, razão e fundamento de toda diferença e exploração social.

Em síntese, para Durkheim e Dewey, pelo viés educacional é possível adequar e/ou inserir o indivíduo no desenvolvimento científico, produtivo e democrático produzido pela sociedade, mas isso não significaria a dissolução do modelo capitalista. Gramsci, baseado na teoria marxista, não acredita que a escola, por si só, poderia construir uma sociedade em que todos, igualitariamente, tivessem acesso aos bens sociais. Para ele, tal pressuposto só é possível com a superação da divisão social e econômica capitalista. Entretanto, esse é um processo constituído tanto na infraestrutura como na luta de classes no campo ideológico e político. Neste sentido, a escola pode contribuir, na medida em que forma teoricamente a classe operária para compreender os fundamentos das contradições capitalista e, numa forma consciente de seu 
lugar e do processo produtivo, buscar a superação do modelo capitalista e a construção do comunismo.

Porém, apesar de toda a profundidade teórica presente nos autores analisados, esse debate não é facilmente delineado. Ele é complexo e carregado de nuances políticas e de perspectivas históricas, as quais, de forma direta ou indireta, constantemente aparecem nos debates atuais. Porém, muitas vezes, sem uma reflexão profunda sobre os problemas, ressoam como um amontoado de chavões políticos.

Neste sentido, retomar a leitura das perspectivas educacionais dos autores supracitados é fundamental, principalmente aos professores que necessitam interpretar tal debate, isto, tanto em suas ações pedagógicas como também em suas implicações na perspectiva de interferir na sociedade.

Nesse caso, o debate sobre as teorias educacionais não se deve limitar ao imediatismo produtivo e/ou ao modismo cultural, mas se exige pensar os fundamentos dos problemas educacionais em relação à estrutura da sociedade. Nesse mesmo aspecto, visto que se está situado em uma sociedade marcada pela divisão social, toda proposta educacional exige a implantação de políticas públicas para que as condições de aprendizagem sejam iguais,

270 bem como o conhecimento escolar, mais do que formar mão de obra para o sistema produtivo, possa oferecer oportunidades para que todos possam analisar criticamente a sociedade, de modo a pensar estratégias e formas de romper com a desigualdade social.

Nesse ínterim, ressalta-se que, na ação educativa, mesmo que os professores não tenham consciência, existem interesses político-sociais. Desta forma, todo professor necessita possuir não só conhecimento científico, mas também conhecimentos das teorias educacionais em relação ao contexto sócio-histórico, ao passo que deve estar atento aos reflexos do ensino no desenvolvimento cognitivo e emocional dos seus alunos. Isso envolve o estudo de várias áreas do conhecimento e uma visão ampla sobre a sociedade em seu processo histórico e determinações sociais.

Para concluir, destaca-se que a escola não é determinante, tampouco inteiramente determinada no processo histórico, mas semelhante a outras instituições, está inserida em um campo de lutas políticas. Assim, contém em si a referida possibilidade de modificar a capacidade de interpretação do sujeito que acolhe. Entretanto, tal sujeito, apesar de atuante socialmente, está inserido 
e delimitado em uma determinada sociedade. Em face do complexo contexto, vale salientar que muitos dos educandos, matriculados na escola pública, só têm nela a possibilidade de desenvolver um olhar crítico. Neste caso, a escola pode assumir um papel de protagonista na capacidade de desenvolver o pensamento crítico.

Nesse sentido, o ensino escolar não pode servir apenas aos interesses do sistema dominante, se adaptando às pequenas mudanças necessárias para a manutenção da ordem. Mas, tal como ensina Antônio Gramsci, é necessário partir da realidade presente, ou seja, da escola atual, com seus problemas e defasagens para que, no conjunto das determinações, se busque as possibilidades de uma atuação consciente para a transformação.

\section{Notas}

1 Criar esse novo hábito para Dewey trata-se de criar uma nova atitude reflexiva, a qual contribua para desenvolver uma nova conduta produtora do conhecimento.

2 Da piccolo ero attrato dai studi delle scienze esatte, ma non ho trovaro un maestro che né valse una moneta (GRAMSCI, 1971).

3 Pedagogo suíço ligado à escola nova.

4 Nas Lettere dal Carcere encontram-se alusões sobre tais revistas que durante algum período foram recebidas por Gramsci no cárcere (GRAMSCI, 1971).

5 Filósofo e historiador italiano.

6 No caderno 04, a citação encontra-se como textos A, ou seja, que será, posteriormente, revisto como textos C. Os textos B são aqueles que não foram, posteriormente, revistos pelo autor nos Cadernos seguintes.

\section{Referências}

ARON, Raymond. As etapas do pensamento sociológico. Tradução Sérgio Bath. São Paulo: Martins Fontes, 2003.

BOMENY, Helena. Quando Durlheim e Dewey se encontram. In: ENCONTRO ANUAL DA ANPOCS, 29, 2005. Caxambu. Anais... Caxambu, 2005. Disponivel em: https://www. anpocs.com/index.php/papers-29-encontro/gt-25/gt06-9/3677-hbomeny-quando/file. Acesso em: 12 nov. 2017.

CUNHA, Marcos Vinícius da. John Dewey: filosofia, política e educação. Perspectiva, Florianópolis, v. 19, n. 2, p. 371-388, jul./dez. 2001. 
DEWEY, John. Democracia e educação: introdução à filosofia da educação. 3. Ed. Tradução Godofredo Rangel e Anísio Teixeira. São Paulo: Nacional, 1959.

DEWEY, John. Experiência e educação. 3. Ed. Tradução Anísio Teixeira. São Paulo: Companhia Editora Nacional, 1979.

DEWEY, John. Experiência e natureza. Tradução Murilo Otávio Rodrigues Paes Lemes. São Paulo: Editora Abril Cultural, 1980.

DEWEY, John. Vida e educação. Tradução Anísio Teixeira. 6. ed. São Paulo: Melhoramentos, 1967.

DURKHEIM, Émile. As regras do método sociológico. Tradução Paulo Neves. São Paulo: Editora Nacional, 1978.

DURKHEIM, Émile. Educação e sociologia. Tradução Stefania Matousek. Petrópolis: Vozes, 2012.

GRAMSCl, Antônio. Cadernos do cárcere. Tradução Carlos Nelson Coutinho. Rio de Janeiro: Civilização Brasileira, 2000.

GRAMSCl, Antonio. Lettere dal carcere. Torino: Einaudi, 1971.

JOVINE, Dina Bertoni. Principi di pedagogia socialista. Roma. Riuniti, 1977.

JYAN, Choy. Étude comparative sur les doctrines pédagogigues de Durkheim et de Dewey. Paris: Bosc Frères \& Riou, 1926.

LEONEL, Zélia. Contribuição à história da escola pública: elementos para a crítica de teoria liberal da educação. 1994. 258f. Tese (Doutorado em Educação) - Programa de PósGraduação da Faculdade de Educação. Campinas: Unicamp, 1994. Disponível em: http: // repositorio.unicamp.br/jspui/handle/REPOSIP/253849. Acesso em: 18 nov. 2017.

LICHTNER, Maurizio. Educare per la democrazia in John Dewey. Scuola democratica, Roma, n. 12, p. 1-13, 2009. Disponível em: http://www.scuolademocratica.it/wpontent/ uploads/2010/09/linkEstratti-da-Dewey-Lichtner-SD_0.pdf. Acesso em: out. 2017.

LOPES, Paula Cristina. Educação, sociologia da educação e teorias sociológicas clássicas. Marx, Durkheim e Weber. Covilhã: Universidade da Beira Interior, 2012.

LUCENA, Carlos. 2010. O pensamento educacional de Émile Durkeim. Revista HISTEDBR, Campinas, n. 40, p. 295-305, dez. 2010. Disponível em: http://www.histedbr.fe.unicamp. br/revista/edicoes/40/art 18_40.pdf. Acesso em: nov 2017. 
MARTINEZ, Daniela. Gramsci e il movimento per l'educazione nuova. Alcuni spunti di reflessione. Studi sulla Formazione, Firenze, n. 1, p. 181-202, 2014. Disponível em: https: / / search. proquest.com/openview/974d5af4e624a066ad080a3ed 127 dc08/1 ?.pq-origsite=gscholar\&cbl=226566. Acesso em: set. 2017.

RAGAZZINI, Dario. Societá industriale e formazione umana nel pensiero di Gramsci. Roma: Riuniti, 1976.

SAVIANI, Demerval. O Plano de desenvolvimento da educação: análise do projeto do MEC. Educação Social, Campinas, v. 28, n. 100, p. 1231-1255. 2007 (Especial).

SCHMIDT, Ireneu Aloisio. John Dewey e a educação para uma sociedade democrática. Contexto \& Educação, ljuí, n. 82, p. 135-154,jul./dez. 2009. Disponível em: https:// www.revistas. unijui.edu.br/index.php/contextoeducacao/issue/view/31. Acesso em out. 2017.

SEBASTIÃO, João. Democratização do ensino, desigualdades sociais e trajectórias escolares. Lisboa: Fundação Calouste Gulbenkian, 2009.

Prof. Dr. Lorivaldo do Nascimento Universidade Estadual do Oeste do Paraná | Toledo | Paraná Centro de Ciências Humanas e Sociais

Pesquisador integrado ao Mestrado em educação da UNIOESTE Membro do Grupo de Pesquisa História e Historiografia da Educação (UNIOESTE) $\mathrm{CNPq}$

E-mail: lorinasci@yahoo.com.br

Prof. Dra. Aparecida Favoreto Universidade Estadual do Oeste do Paraná | Cascavel | Paraná Centro de Educação Comunicação e Artes Docente e pesquisadora do Mestrado em Educação da UNIOESTE Membro e líder do Grupo de Pesquisa História e Historiografia na Educação (UNIOESTE| CNPq) E-mail: cidafavoreto@globo.com

Recebido 10 abr. 2018 Aceito 8 jun. 2018 